\title{
Konsentrasi Klorofil-a dan Keterkaitannya dengan Nutrient N, P di Perairan Jepara : Studi Perbandingan Perairan Muara Sungai Wiso dan Serang
}

\author{
Lilik Maslukah*, Sri Yulina Wulandari dan Indra Budi Prasetyawan \\ Departemen Oseanografi, Fakultas Perikanan dan Ilmu Kelautan, Universitas Diponegoro \\ JI. Prof. Soedarto, SH. Kampus UNDIP Tembalang, Semarang 50275 \\ Email : lilik_masluka@yahoo.com
}

\begin{abstract}
The existenece of nutrient is highly affected by human activities and causing the amount of chlorophyll-a which is the indicator of water fertility. Muara Wiso is a location located in the urban center of Jepara while Serang estuary is mostly impacted by agriculture activities in the upper area. This study has compared the concentration of chlrorophyll-a and its association with $\mathrm{N}$ and $\mathrm{P}$ nutrients in the two different environmental conditions in Jepara waters. Nutrient $N$ was determined as a nitrite ion using the sulphanilamide method after it was reduced using a reduction column. $P$ was determined as orthophosphate using ascorbic acid and chlorophyll-a method which were extracted from water sample filtrate, using $90 \%$ acetone. The results showed that the mean of $N, P$ concentration of Wiso estuary was 1.3285 $\pm 0.33 \mathrm{mg} \mathrm{N} / \mathrm{l}, 0.4723 \pm 0.27 \mathrm{mg} P / /$ and Serang estuary was $0.0172 \pm 0.005 \mathrm{mg} \mathrm{N} / \mathrm{l}, 0.3813 \pm$ $0.21 \mathrm{mg} P / \mathrm{l}$. The N/P ratio of Serang estuary has a higher value than Wiso. This condition caused the chlorophyll-a concentration at Serang estuary is twice higher than at Wiso. The abundance of chlorophyll-a concentration at Serang estuary is more affected by higher nutrient load of $N$.
\end{abstract}

Keywords : Nutrients N, P, Chlorophyll-a, Wiso and Serang

\begin{abstract}
Abstrak
Keberadaan nutrien sangat dipengaruhi oleh aktivitas manusia dan dapat menyebabkan tingginya nilai konsentrasi klorofil-a yang merupakan indikator kesuburan perairan. Muara Wiso merupakan lokasi yang terletak di pusat perkotaan Jepara, sedangkan muara Serang lebih mendapatkan pengaruh dari aktivitas pertanian di daerah hulunya. Penelitian ini telah membandingkan konsentrasi klorofil-a dan keterkaitannya dengan nutrient $\mathrm{N}$ dan $\mathrm{P}$ pada dua kondisi lingkungan yang berbeda di perairan Jepara. Nutrien $\mathrm{N}$ ditentukan sebagai ion nitrit menggunakan metode sulphanilamide setelah direduksi menggunakan kolom reduksi. P ditentukan sebagai orthophosphate menggunakan metode asam askorbit dan klorofil-a diekstrak dari filtrate sampel air yang diekstrak menggunakan aseton 90\%. Hasil penelitian menunjukan bahwa rerata konsentrasi $\mathrm{N}, \mathrm{P}$ di muara Wiso $1.3285 \pm 0.33 \mathrm{mg} \mathrm{N} / \mathrm{l}, 0.4723 \pm 0.27 \mathrm{mg} P / /$ dan di muara Serang $0.0172 \pm 0.005 \mathrm{mg} \mathrm{N} / \mathrm{l}, 0.3813 \pm 0.21$ $\mathrm{mg} P / \mathrm{l}$. Rasio N/P muara Serang mempunyai nilai lebih tinggi dibanding Wiso. Kondisi ini menyebabkan konsentrasi klorofil-a muara Serang dua kali lebih tinggi dibanding Wiso. Tingginya klorofil-a di muara Serang lebih dipengaruhi nilai beban nutrient $N$ yang lebih tinggi.
\end{abstract}

Kata Kunci : Nutrient N, P, klorofil-a, Wiso and Serang

\section{PENDAHULUAN}

Hasil dari program 10 tahunan LOICZ (Land Ocean in the Coastal Zone) secara jelas menyatakan bahwa dampak aktivitas manusia terhadap sistem pesisir sangat nyata (Siregar \& Koropitan, 2016). Tingginya aktivitas manusia telah 
memberikan pengaruh nyata terhadap peningkatan masukan bahan pencemar ke perairan muara (Cong et al., 2003; William et al., 2010; Utomo et al., 2013; Utami et al., 2015,). Kontribusi bahan pencemar organik dalam limbah cair yang berasal dari aktivitas manusia telah mencapai $50 \%$ sampai $75 \%$ dari limbah cair total (Putnam et al., 2010).

Dampak ekologis masuknya limbah organik dari daratan ke muara sungai membuat perairan menjadi lebih subur akibat peningkatan nutrient $N$ dan $P$. Nutrien ini merupakan substansi yang sangat berperan sangat nyata dalam proses dan perkembangan organisme hidup seperti fitoplankton (Wang et al., 2015; Wisha dan Maslukah, 2017).

Kesuburan perairan yang tinggi memiliki dampak positif dan jika kondisinya terlalu subur akan berdampak negatif (Domingues et al., 2011; Simanjuntak dan Kamiasi, 2012). Dampak positif, yaitu membawa manfaat yang tinggi bagi masyarakat, khususnya nelayan, karena melimpahnya plankton dan mengakibatkan produksi ikan menjadi tinggi. Sementara dampak negatif akan menimbulkan kematian massal ikan melalui berkurangnya oksigen terlarut atau timbulnya zat beracun seperti nitrit, ammonia dan hidrogen sulfida (H2S) akibat penguraian secara an aerob Maslukah et al., (2014).

Hasil penelitian Maslukah et al. (2016) menyatakan bahwa kontribusi $\mathrm{N}$ dan $P$ dari sungai Wiso dan Serang ke perairan Jepara sebesar 19,66 ton/bulan dan 2,15 ton/bulan. Hal ini akan berakibat mempengaruhi nilai produktivitas primer perairan. Klorofil-a merupakan komponen terbesar dalam fitoplankton yang bertanggung jawab terhadap aktivitas produktivitas primer.

Sungai Wiso dan Sungai Serang merupakan sungai yang bermuara ke Perairan Jepara dengan kondisi daerah aliran sungai yang berbeda. Sungai Wiso mengalir melewati daerah perkotaan dengan penduduk yang relatif padat, sedangkan Sungai Serang mengalir melalui area pertanian (Maslukah et al., 2016). Kondisi daerah aliran yang berbeda dapat mempengaruhi konsentrasi nutrien $\mathrm{N}$, P dan selanjutnya dapat mempengaruhi konsentrasi klorofil-a.

Berdasarkan latar belakang tersebut perlu dilakukan penelitian mengenai konsentrasi klorofil-a dan keterkaitannya dengan nutrient di Perairan Jepara, khususnya perairan muara sungai Wiso dan Serang. Diharapkan penelitian ini dapat memberikan informasi terkini tentang kondisi produktivitas primer di Perairan Jepara, yang selanjutnya dapat digunakan sebagai acuan untuk melihat perkembangan kondisi produktivitas primer perairan dan fluktuasinya.

\section{MATERI DAN METODE}

Lokasi penelitian meliputi dua muara sungai yaitu: muara Sungai Wiso dan Serang, Kabupaten Jepara (Gambar 1). Penelitian dilaksanakan pada Mei 2017.

Penentuan lokasi penelitian dilakukan secara purposive sampling (pertimbangan). Pada tahap ini lokasi pengambilan sampel air ditetapkan berdasarkan penelitian sebelumnya oleh Maslukah et al. (2016). Dari kedua lokasi tersebut dibagi dalam beberapa 10 stasiun dengan pertimbangan : stasiun 1 dibadan sungai, stasiun 2 dan 3 pada muara sungai, serta stasiun 4 sampai 10 di perairan pantai. Pengambilan sampel dilakukan pukul 09.00-14.00.

Sampel air diambil dengan menggunakan water sampler dari permukaan $(0,2 D, D=$ kedalaman perairan). Sampel untuk analisis nutrient dan klorofil dipindahkan ke botol sampel polytene. Sebelum diisi, botol dicuci menggunakan air sampel yang sama. Setelah sampai di laboratorium, sebanyak $500 \mathrm{ml}$ sampel dilakukan penyaringan dengan kertas saring Millipore (size pore $0,45 \mu \mathrm{m})$. Pada umumnya sampel langsung dianalisis pada hari yang sama. Namun demikian apabila tidak memungkinkan untuk dilakukan analisis pada hari yang sama, sampel dapat dibekukan dan dianalisis pada hari berikutnya (Chale, 2004). 


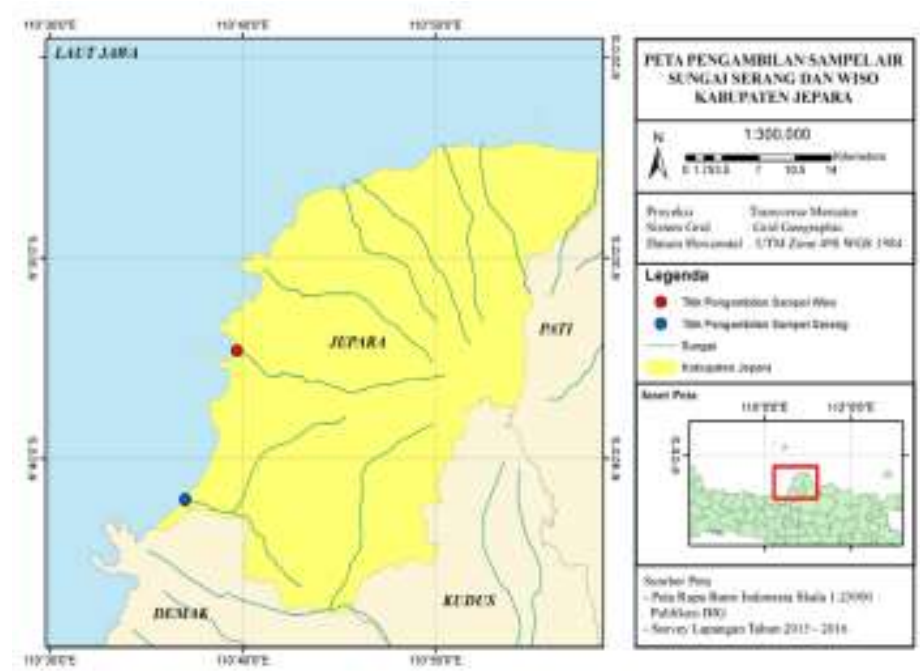

Gambar 1. Lokasi Penelitian (Maslukah, 2016)

Nutrien $\mathrm{N}$ ditentukan sebagai ion nitrit menggunakan metode sulphanilamide (Wetzel \& Likens, 1991) setelah direduksi menggunakan kolom reduksi (tembaga-cadmium) (Mackereth et al., 1989). Nutrient $P$ terlarut ditentukan sebagai orthophosphate menggunakan metode asam askorbit (APHA, 1992). Kedua nutrient ini ditentukan nilai absorbansinya menggunakan spektrofotometer UV-VIS Shimadzu 3600, dengan lebar cuvet $1 \mathrm{~cm}$.

Sebanyak 1 liter air laut disaring mengunakan kertas saring millipore (size pore $0,45 \mu \mathrm{m})$. Filtrat yang tersaring diekstrak menggunakan $10 \mathrm{ml}$ aseton $90 \%$. Dibiarkan selama satu malam dalam almari es dengan kondisi gelap selama 16 jam. Selanjutnya disentrifuse dengan putaran $4000 \mathrm{rpm}$. Supernatannya dibaca nilai absorbansinya pada panjang gelombang 665. Panjang gelombang 750 digunakan sebagai kontrol kekeruhan. Konsentrasi klorofil-a dihitung dengan formula berikut :

$$
\begin{aligned}
& \mathrm{Ca}=26,7(665 a-665 \mathrm{~b}) \\
& \mathrm{Klo}-\mathrm{a}\left(\mathrm{mg} / \mathrm{m}^{3}\right)=\mathrm{Ca} \times \mathrm{v} / \mathrm{V} \times 1
\end{aligned}
$$

Keterangan :

665 a dan $665 \mathrm{~b}=$ pembacaan nilai absorbansi pada panjang gelombang tersebut sebelum dan sesudah ditambahkan asam Parson et al, 1992)

$v=$ volume ekstrak (liter)

$\mathrm{V}=$ volume sampel $\left(\mathrm{m}^{3}\right)$

$1=$ lebar cuvet $(\mathrm{cm})$

\section{HASIL DAN PEMBAHASAN}

Hasil penelitian menunjukkan bahwa konsentrasi $\mathrm{N}$ terlarut di muara Serang berkisar antara 0,0129-0,0299 mg/l dengan nilai rerata $0,0172 \mathrm{mg} / \mathrm{l}$ dan $\mathrm{P}$ berkisar 0,0073-0,0273 mg/l dengan nilai rerata $0,0118 \mathrm{mg} / \mathrm{l}$. Konsentrasi $\mathrm{N}$ dan $\mathrm{P}$ ini lebih tinggi terlihat pada muara Wiso dengan kisaran nilai antara 0,0151-0,0255 $\mathrm{mg} / \mathrm{l}$ (rerata 0,0186 mg/l ) dan P antara 0,0023-0,0328 mg/l (rerata 0,0146 mg/l). Keberadaan kedua nutrient ini mempengaruhi konsentrasi klorofil yang terukur. Muara Serang menunjukkan kisaran nilai klorofil $0,80-3,20 \mathrm{mg} / \mathrm{m}^{3}$ (rerata $1,76 \mathrm{mg} / \mathrm{m}^{3}$ ) dan Wiso berkisar 0,27-1,87 $\mathrm{mg} / \mathrm{m}^{3}$ (rerata $0,91 \mathrm{mg} / \mathrm{m}^{3}$ ). Hasil selengkapnya berkaitan dengan fluktuasinya pada setiap stasiun disajikan pada Gambar 2 dan 3.

Berdasarkan Gambar 2 dapat dilihat bahwa konsentrasi nutrien $\mathrm{N}$ dan $\mathrm{P}$ di muara sungai Wiso (w1-w10) menunjukkan nilai yang lebih tinggi dibanding dengan muara Serang (s1-s10). Kondisi ini sama dengan hasil penelitihan sebelumnya yang dilakukan oleh Maslukah et al (2016), meskipun konsentrasinya menunjukkan lebih tinggi.

Tingginya konsentrasi nutrien $\mathrm{N}$ dan $\mathrm{P}$ di muara sungai Wiso sangat berkaitan dengan lokasinya yang berada di pusat perkotaan Kabupaten Jepara. Disepanjang aliran daerah sungainya 
banyak aktivitas rumah tangga yang membuang limbah rumah tangganya ke perairan tersebut. Salah satu buangan limbah dari aktivitas penduduk yang paling besar adalah senyawa nitrogen, yang bersumber dari sisa metabolisme. Seperti halnya dikota-kota lainnya, disepanjang aliran sungai ini banyak penduduk yang bermukim dan langsung membuang sisa hasil aktivitas rumah tangganya ke perairan.

Perairan muara Wiso dan Serang, Jepara termasuk dalam kategori eutropik berdasarkan konsentrasi nutrient $\mathrm{N}$ dan $\mathrm{P}$ rerata. Kategori ini berdasarkan klasifikasi menurut Ignatiades et al. (1992), dengan kisaran nilai $>0,007 \mathrm{mg} \mathrm{N} / \mathrm{l}$ dan $>0,011 \mathrm{mg}$ $\mathrm{P} / \mathrm{l}$.

Secara umum kondisi rerata nutrient $N$ dan $P$ perairan Wiso dan Serang menunjukkan nilai yang sedikit lebih tinggi (Tabel 1). Konsentrasi rerata nutrient $\mathrm{N}$
Serang dan Wiso mempunyai selisih \pm $0.0014 \mathrm{mg} / \mathrm{l}$ dan $\mathrm{P} \pm 0.0028 \mathrm{mg} / \mathrm{l}$. Muara Serang memiliki konsentrasi klorofil-a lebih tinggi, meskipun memiliki nutrient yang sedikit lebih rendah. Hal ini berkaitan dengan keberadaan sungai dan muaranya yang jauh lebih besar dibanding Wiso. Berdasarkan luas daerah aliran sungai, sungai Serang memiliki daerah aliran sungai (DAS) seluas 138,26 km2 dengan panjang sungai $32,28 \mathrm{~km}$, sedangkan sungai Wiso DAS nya hanya seluas $38,71 \mathrm{~km} 2$ dengan lebar sungai $29,24 \mathrm{~km}$ (http://bpsdaseluna.jatengprov. go.id/database/das.php). Hasil penelitian Maslukah (2016) menyatakan bahwa beban nutrient (load) sungai Serang sebesar 30,086 ton N/bulan dan 2,2 ton $\mathrm{P} /$ bulan. Tingginya beban $\mathrm{N}$ yang masuk ke muara Serang menyebabkan rasio N/P menjadi sedikit lebih tinggi (Table 2). Daerah hulu Sungai Serang merupakan daerah pertanian yang diduga adanya penggunaan pupuk yang berlebih. Cong

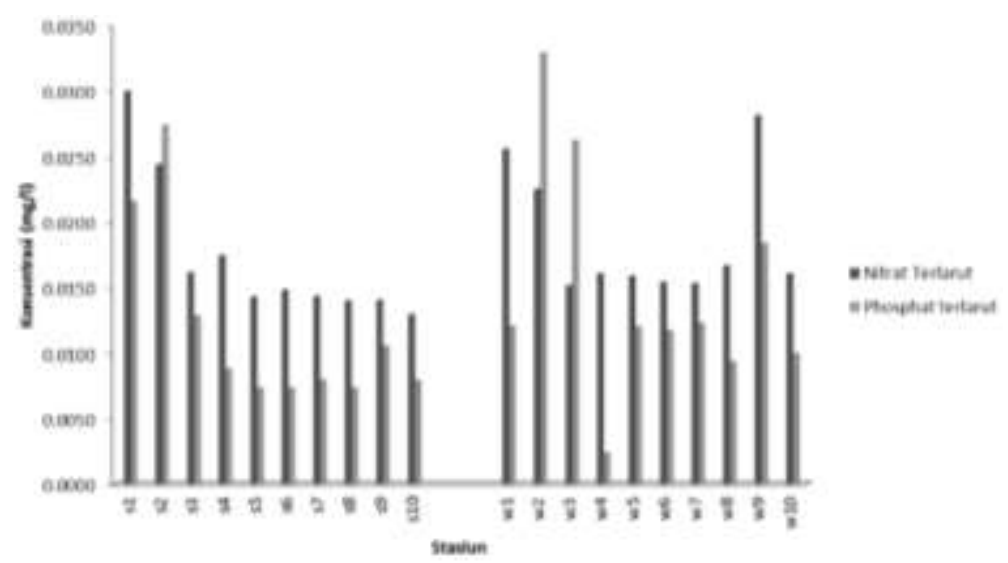

Gambar 2. Konsentrasi Nitrat terlarut dan Phospat terlarut

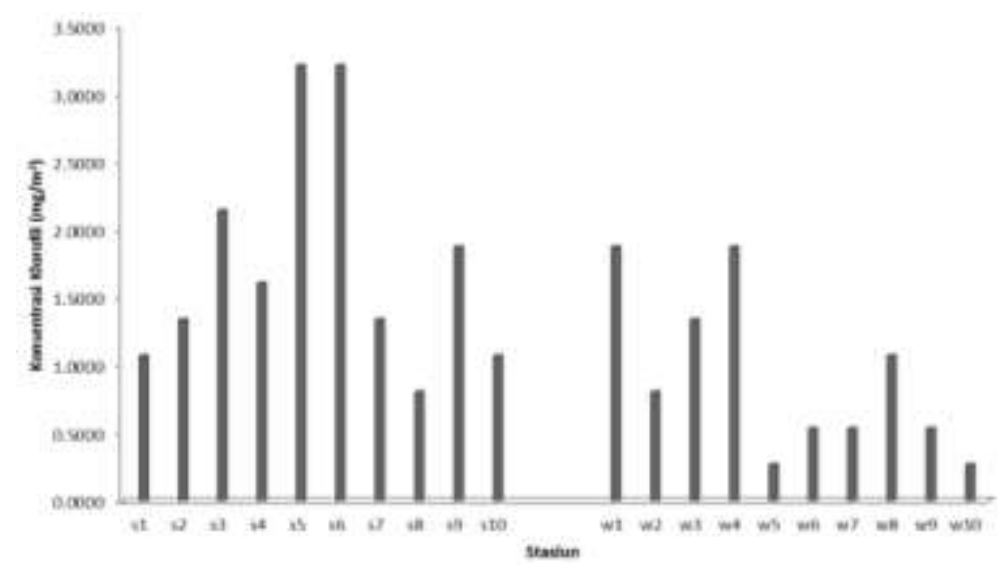

Gambar 3. Konsentrasi Klorofil-a pada stasiun Serang dan Wiso 
Tabel 1. Konsentrasi rerata N, P dan klorofil-a perairan Serang dan Wiso

\begin{tabular}{lllll}
\hline \multicolumn{1}{c}{ Lokasi Penelitian } & \multicolumn{1}{c}{$\mathrm{N}(\mathrm{mg} / \mathrm{l})$} & \multicolumn{1}{c}{$\mathrm{P}(\mathrm{mg} / \mathrm{l})$} & \multicolumn{1}{c}{ Rasio N/P } & \multicolumn{1}{c}{ Klorofil $\left(\mathrm{mg} / \mathrm{m}^{3}\right)$} \\
\hline Rerata Serang & $0.0172 \pm 0.005$ & $0.0118 \pm 0.007$ & 1.46 & $1,76 \pm 0,86$ \\
Rerata Wiso & $0.0186 \pm 0.005$ & $0.0146 \pm 0.008$ & 1.27 & $0,91 \pm 0,61$ \\
Selisih Serang dan Wiso & 0.0014 & 0.0028 & & 0.85 \\
\hline
\end{tabular}

Tabel 2. Konsentrasi N dan P di Perairan Indonesia

\begin{tabular}{lccl}
\hline \multicolumn{1}{c}{ Lokasi Penelitian } & $\begin{array}{c}\text { Rerata konsentrasi } \\
\mathrm{P}(\mathrm{mg} / \mathrm{l})\end{array}$ & $\begin{array}{c}\text { Rerata konsentrasi } \\
\mathrm{N}(\mathrm{mg} / \mathrm{l})\end{array}$ \\
\hline Muara Serang & $0.0118 \pm 0.007$ & $0.0172 \pm 0.005$ & Hasil Penelitian ini \\
Muara Wiso & $0.0146 \pm 0.008$ & $0.0186 \pm 0.005$ & Hasil Penelitian ini \\
Teluk Hurun, Lampung & $0.0037-0.0042$ & 0.001 & Santoso (2006) \\
Teluk Banten & $0.05-0.007$ & $0.001-0.16$ & Alianto et al. (2009) \\
Teluk Ujungbatu, Jepara & 0.2 & 0.51 & Karil et al. (2015) \\
Teluk Jakarta & 0.23 & 0.06 & Yuliana (2012) \\
Karimunjawa & 0.11 & 0.37 & Ulaodry et al. (2010) \\
\hline
\end{tabular}

et al., (2006) menyatakan bahwa adanya pengaruh daratan menyebabkan tingginya masukan nutrient ke perairan pantai. Beberapa penelitian konsentrasi $N$ dan P yang pernah dilakukan di Indonesia dapat dilihat pada Tabel 2.

Huang et al., (1990) menggambarkan korelasi hubungan dua variable lemah jika nilai korelasi $(|r|<0,3)$, rendah jika $(0,3<|r|<0,5)$, sedang $(0,5<|r|<0,8)$ dan kuat $(0,3<|r|<0,5)$. Berdasarkan hubungan ini, klorofil-a dengan nutrient $N, P$ menunjukkan hubungan lemah negatif $(r<0,3)$. Secara umum kedua lokasi menunjukkan korelasi positif terhadap rasio molar N/P. Hasil penelitian Chale (2004) di perairan danau mendapatkan hubungan negatif klorofil-a terhadap nitrat dan positif terhadap phosphate dan molar rasio N/P. William et al., (2010) menyatakan bahwa dalam skala lokal, nutrient tidak selalu menimbulkan respon mengubah biomassa fitoplankton (dalam penelitian ini tidak mengubah konsentrasi klorofil disetiap stasiun penelitian).

\section{KESIMPULAN}

Hasil Penelitian menunjukkan bahwa konsentrasi klorofil-a perairan Serang memiliki nilai dua kali lebih tinggi dibanding perairan Wiso. Kondisi ini disebabkan adanya hasil rasio N/P yang lebih tinggi di muara Serang. Berdasarkan analisis hubungan korelasi didapatkan bahwa rasio nutrient N/P terhadap klorofil memiliki korelasi yang positif.

\section{UCAPAN TERIMAKASIH}

Penulis mengucapkan terima kasih kepada Universitas Diponegoro yang telah memberi bantuan melalui dana selain APBN DPA SUKPA LPPM Universitas Diponegoro tahun anggaran 2017.

\section{DAFTAR PUSTAKA}

Alianto, Adiwilaga, E.M., Damar, A. \& Harris, E.. 2009. Pengukuran nutrien inorganik terlarut di zonaeufotik perairan Teluk Banten. Indo. J. Chem. 9 (2):217-25.

APHA. 1992. Standart method for the examnination of water dan wastewater. $18^{\text {th }}$ edition. Washington, $252 \mathrm{p}$

Chale, F.M.M. 2004. Inorganic nutrient concentrations and chlorophyll in the euphotic zone of Lake Tanganyika. Hydrobiologia. 523: 189-197

Cong, P.F., Niu, Z., Meng, J.H. \& Li, X.J. 2006. Variability of chlorophyll-a retrieved from satellite in Chinese Shelf Sea from 1998 To 2003. Mar. Environ. Sci. 25 : 30-33.

Domingues, R.B., Anselmo, T.P. \& Barbosa, A.B. 2011. Nutrient limitation of phytoplankton growth in the freshwater tidal zone of a turbid, Mediterranean Estuary. Est. Coast. 
Shelf Sci. 91 (2):282-297. doi: 10.1016/j. ecss.2010. 10.033.

Huang, H.J. 1990. Investment Big Dictionary; Shanghai social science press. Beijing, China, pp: 311-312.

Ignatiades, L., Karydis, M. \& Vounatsou, P. 1992. A possible method for evaluating oligotrophy and eutrophication based on nutrient concentrations. Mar. Poll. Bull. 24(5): 238-243.

Mackereth, F.J.H., Heron, J. \& Talling, J.F. 1989. Water analysis: Some revised methods for Limnologists, $2^{\text {nd }}$ impression. FBA Scientific publications No. 36, Titus Wilson \& Son Ltd., Kendal.

Karil, A.R, Yusuf, M. \& Maslukah, L. 2015. Studi Sebaran Konsentrasi Nitrat dan Fosfat di Perairan Teluk Ujungbatu Jepara. J. Oseano. 4:386-392.

Maslukah, L., Indrayanti, E. \& Rifai, A. 2014. Sebaran material organik dan zat hara oleh arus pasang surut di muara sungai Demaan, Jepara. Ilmu Kelautan. 19(4): 189-194

Maslukah, L, Wulandari, S.Y. \& Prasetyawan, I.B. 2016. Kontribusi nutrien $\mathrm{N}$ dan $\mathrm{P}$ dari sungai Serang dan Wiso ke perairan Jepara. Prosiding seminar nasional hasil-hasil penelitian perikanan dan kelautan keVI. Fakultas Perikanan dan IImu Kelautan - Pusat Kajian Mitigasi Bencana dan Rehabilitasi Pesisir, Undip. pp : 183-191

Parsons, T.R., Y. Maita and C.M. Lalli. 1984. A manual of Chemical and Biological Methods for Seawater Analysis. USA: Pergamon Press.

Putnam, L.A, Gambrell, R.P. \& Rusch, K.A. 2010. CBOD5 Treatment using the Marshland Upwelling Sistem. Ecolog. Eng. 36:548-559.

Santoso, A.D. 2006. Kualitas nutrien perairan Teluk Hurun, Lampung. J. Tek. Ling. 2:140-44.

Simanjuntak, M. \& Kamlasi, Y. 2012. Sebaran horisontal zat hara di
Perairan Lamalera, Nusa Tenggara Timur. Ilmu Kelautan. 17(2):99-108.

Siregar, V., \& Koropitan, A.F. 2016. Land use change and its impact to marine primary production in Semarang Waters. Proc. Environ. Sci. 33:20-531.

Utami, T,M,T., Maslukah, L. \& Yusuf, M.. 2016. Sebaran nitrat (NO3) dan fosfat (PO4) di Perairan Karangsong Kabupaten Indramayu. Bul. Oseano. Mar. 5(1):31-37.

Ulqodry, Yulisman, T.Z., Syahdan, M. \& Santoso. 2010. Karakterisitik dan sebaran nitrat, fosfat, dan oksigen terlarut di Perairan Karimunjawa Jawa Tengah. J. Penelitian Sains. 13:35-41

Utomo, Y., Priyono, B. \& Ngabekti, S. 2013. Saprobitas perairan sungai Juwana berdasarkan bioindikator plankton. Unnes J. Life Sci. 2(1):28-35.

Wang, Y., Jiang, H., Jin, J., Zhang, X., Lu, X. \& Wang, Y. 2015. Spatial-temporal variations of chlorophyll-a in the adjacent sea area of the Yangtze River Estuary influenced by Yangtze river ischarge. Int. J. Environ. Res. Public Health. 12:5420-5438

Wetzel, R.G. \& Likens, G.E. 1991. Limnological Analysis, 2nd.edn. Springer-Verlag, New York.

William, Li, K.W., Marlon, Lewis, R. \& Harrison, W.G. 2010. Multiscalarity of the nutrient-chlorophyll relationship in coastal phytoplankton. Estuaries and Coasts. 33:440-447

Wisha, U.J. \& Maslukah, L. 2017. Nutrient condition of Kampar Big River Estuary: Distribution of $\mathrm{N}$ and $\mathrm{P}$ concentrations drifted by tidal bore "Bono". IImu Kelautan, 22(3):137-146

Yuliana. 2012. Implikasi Perubahan Ketersediaan Nutrien Terhadap Perkembangan Pesat Fitoplankton di Teluk Jakarta. Desertasi: Bogor Agricultural University, 1-178. 